\title{
A PROBLEM WITH AN INTEGRAL BOUNDARY CONDITION FOR A TIME FRACTIONAL DIFFUSION EQUATION AND AN INVERSE PROBLEM
}

\author{
HALYNA LOPUSHANSKA
}

\begin{abstract}
For a linear inhomogeneous time fractional diffusion equation on bounded cylindrical domain the problem with an integral boundary condition is studied. The inverse problem for the restoration of the whole right-hand side of the equation is also studied. The conditions of the solvability and the unique solvability of these problems are founded.
\end{abstract}

Mathematics subject classification (2010): 35S10.

Keywords and phrases: Fractional derivative, integral boundary condition, inverse problem, Green vector-function, integral equation.

\section{REFERENCES}

[1] T. S. Aleroev, M. Kirane, S. A. Malik, Determination of a source term for a time fractional diffusion equation with an integral type over-determination condition, Electronic J. of Differential Equations, 2013 (2013), no. 270, 1-16.

[2] M. M. DJRbashian, A. B. Nersessyan, Fractional derivatives and Cauchy problem for differentials of fractional order, Izv. AN Arm. SSR. Matematika, 3 (1968), 3-29.

[3] A. N. KochubeI, Fractional-order diffusion, Differential Equation, 26 (1990), 485-492.

[4] S. D. Eidelman, S. D. IVASyshen, A. N. KochubeI, Analytic methods in the theory of differential and pseudo-differential equations of parabolic type, Birkhauser Verlag, Basel-Boston-Berlin, 2004.

[5] A. Friedman, Partial differential equations of parabolic type, Prentice-Hall, Englewood Cliffs, N. J., 1964.

[6] Y. Hatano, J. Nakagawa, Sh. Wang And M. Yamamoto, Determination of order in fractional diffusion equation, Journal of Math-for-Industry 5A (2013), 51-57.

[7] H. LOPUSHANSKa, A. LOPUSHANSKY, E. PASICHNYK, The Cauchy problem in a space of generalized functions for the equations possessing the fractional time derivarive, Sib. Math. J. 52 (2011), no. 6, 1288-1299.

[8] H. LOPUSHANSKA, V. RAPITA, Inverse coefficient problem for semi-linear fractional telegraph equation, Electronic J. of Differential Equations, 2015 (2015), no. 153, 1-13.

[9] A. O. Lopushansky, H. P. LOPUShansKa, One inverse boundary value problem for diffusionwave equation with fractional derivarive, Ukr. Math. J. 66, 5 (2014), 655-667.

[10] YU. Luchкo, Maximum principle for the generalized time-fractional diffusion equation, J. Math. Anal. Appl. 351 (2009), 409-422.

[11] M. M. Meerschaert, ERKan NAne, P. Vallaisamy, Fractional Cauchy problems on bounded domains, Ann. Probab. 37 (2009), 979-1007.

[12] J. NAKAgawa, K. SAKAмото AND M. YAmamoto, Overview to mathematical analysis for fractional diffusion equation - new mathematical aspects motivated by industrial collaboration, Journal of Math-for-Industry 2A (2010), 99-108.

[13] W. Rundell, X. XU AND L. Zuo, The determination of an unknown boundary condition in fractional diffusion equation, Applicable Analysis 92, 7 (2013), 1511-1526.

[14] A. A. Voroshylov, A. A. Kilbas, Conditions of the existence of classical solution of the Cauchy problem for diffusion-wave equation with Caputo partial derivative, Dokl. Ak. Nauk 414, 4 (2007), 1-4. 
[15] Y. ZhANG AND X. XU, Inverse source problem for a fractional diffusion equation, Inverse Problems 27 (2011), 1-12. 